\title{
Transatlantic Online Community of Practice
}

\author{
http://dx.doi.org/10.3991/ijet.v7i3.2213 \\ Barbara Schwarz-Bechet ${ }^{1}$, Roelien Bos-Wierda ${ }^{2}$, Ron Barendsen ${ }^{2}$ \\ ${ }^{1}$ University of Maryland University College, Maryland, USA \\ ${ }^{2}$ NHL University of Applied Science, Leeuwarden, The Netherlands
}

\begin{abstract}
Global citizenship and an international orientation are high on the agenda in higher education both in Europe and in the USA. The realization of ambitions in this sphere is often problematic since student and staff exchange is a costly and time consuming affair. In this paper we will explore to what extent the use of technology may facilitate this process and what the added value is. To that end we will demonstrate how a university in the Netherlands and a university in the United States began a partnership in the area of teacher education. Through the use of technology, faculty and student teachers in the Netherlands and the USA socialize and collaborate on the secure educational platform $\mathrm{My}$ schoolsnetwork.com. We will focus on the relationship between the social and the professional, the formal and the informal. We will demonstrate how parts of the US and NL curricula were synchronized and how students on both sides of the Atlantic uploaded lesson plans, webquests and classroom dilemmas.
\end{abstract}

We will discuss why and how we began our partnership and provide detailed instructions on how to achieve success in the development in a transatlantic partnership. and explore what factors determine success or failure. In the conclusion plans for the future will be described.

Index Terms - Internationalization, online communities of practice, informal learning

\section{INTRODUCTION}

The current world system of globalization encourages partnership at many levels [1]. There is increasing encouragement at universities to internationalize their institutions. Institutes of higher education have been engaging with global partners through more teaching and research collaboration [2].

\section{A. Description NHL University of Applied Sciences in the Netherlands.}

The NHL has four different Faculties, one of which (Institute of Education and Communication) offers graduate (BA) and postgraduate (MA) teaching programs for Languages, (Dutch, English, French, German, Frisian) Science (Biology, Physics, Maths, Chemistry) and Social Studies.(Geography, History, Economics, Health Care) Besides content knowledge and professional training, there is a strong focus on educational technology and ITdidactics. Staff and students of the NHL have developed MySchoolsNetwork to realize a variety of didactic and strategic goals:

- to offer a virtual but authentic learning environment to students to practice their feedback, coaching and assessment skills.
- to offer an attractive and authentic social platform to schools and their pupils to get to know other cultures and to practice their language skills.

- to strengthen the relationship between the NHL and their network of professional development schools.

- to offer a virtual "intervision" environment for students and expert teachers to engage in peer consultation activities.

- to foster cross-border learning activities and to promote the development of international learning communities.

These ambitions are in line with recommendations of the European Council that education should aim at Life Long Learning and the development of 8 Key Competencies, of which Global Citizenship and mastery of foreign languages are examples.

\section{B. Description of Maryland University College/MAT}

\section{University of Maryland University College}

The Masters of Arts in teaching program at University of Maryland University College began in Fall 2009 providing opportunities for individuals with an undergraduate degree in biology, chemistry, earth/space science, English, foreign languages, computer science, history, mathematics, physics, or social studies to obtain a graduate degree in secondary education, leading to Maryland State certification in their content area.

To support the MAT teacher candidates, a mentoring program was developed to assist not only the teacher candidates to better understand how to teach their content knowledge and support their understanding of learning communities, but also to provide professional development in the area of technology tools to master teachers in the field who mentor the teacher candidates. We have a website where both prospective mentors, both national and international, and mentees can learn more about the program and how to apply.

As part of the mission, of the UMUC MAT program, it is imperative to include global learning as required goal of the MAT program. President Barack Obama has called for American schools to align student achievement with the demands of the global economy, thereby ensuring, through education, that all students be globally competent is an imperative [3]. Meeting with the faculty from the NHL University's institute of Education and Communication, allowed for collaboration on several initiatives to integrate global learning and technology integration into the program and become part of the international learning community. 


\section{HISTORY OF PARTNERSHIP}

\section{A. How we the partnership started}

Representatives from both Universities were present at the ICELW 2011 conference in New York. UMUC MAT were giving a presentation on their online mentoring program whereas the NHL did two workshops on online coaching and online peer consultation.

We were present during each other's workshops and soon discovered that in spite of the fact that we work in different parts of the world we share views and beliefs on how education and students may benefit from - especially - the collaborative possibilities of modern technology. During the conference dinner we agreed to be in touch by means of Skype once we were back in our own countries to see how we might collaborate in order to bring in an extra dimension for our students.

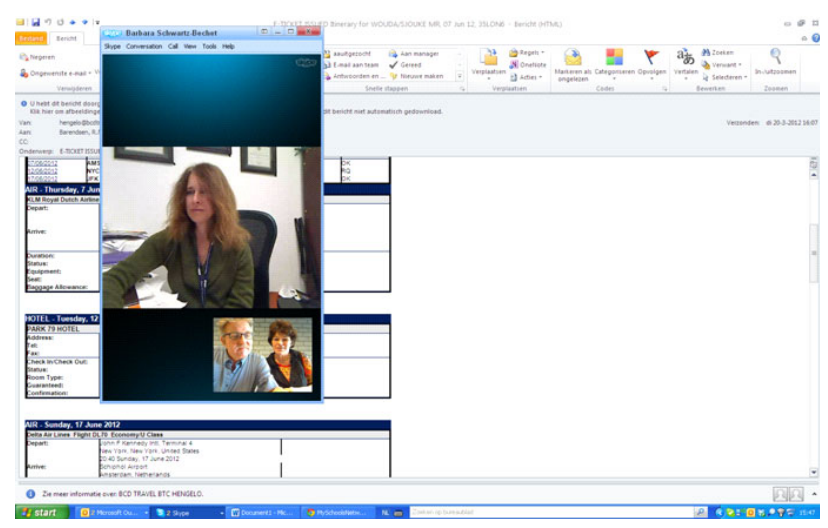

Figure 1. Representation of Skype Session

Two weeks after the conference a Skype session was organized for 2 UMUC faculty and two NHL lecturers. This is how it started and we have been Skyping on a regular basis ever since.

\section{B. Partnership and overall collaboration plan}

During our first two video conferences we decided that we would formulate a number of pilot plans for online collaboration of NHL and UMUC students. We generally agreed that MAT and NHL students would work together primarily on www.myschoolsnetwork.com. One pilot would use the UMUC Webtycho platform (www.tychousa.umuc.edu/). In addition, we agreed to synchronize our programs wherever possible. We shared our due dates of assignments as well as the dates of the beginning and the end of the semester in order to insure that the pilots could be successful. The plan developed organically and online by means of Googledocs (www.docs.google.com). A Memorandum of Understanding between the two universities was drawn up and signed by the higher administration in both universities. In this way a degree of commitment was ensured from multiple levels within each institution.

\section{The pilot plans}

We developed an overall plan comprising three smaller pilot plans. Communities of Practice will not work unless there is a proper socialization phase [4]. To that end NHL and UMUC students participated in the online event "Why I love teaching" for which they were invited to upload a short story describing what or who inspired them to want to become a teacher. Students commented on each other's stories and shared views and experiences.

For pilot A students were invited to upload the webquests, they were required to develop, on MySchoolsnetwork. For pilot B students had to collaborate online in mixed transatlantic groups to analyze a video with a focus on education and present their findings in a website. For pilot $C$ students on either side of the ocean were giving peer feedback and advice to each other about classroom dilemmas encountered during traineeships.

\section{EXECUTION OF THE PILOTS}

\section{A. The webquest pilot}

Pilot A invited students to publish their completed webquest, for a grade in the MAT class, to MySchoolsNetwork so as to share their work with a larger audience of educators for the purpose of peer advisement, learning about new or different Web 2.0 tools that were used to create the webquest, and to develop relationships with teacher candidates to better understand another culture. The teacher candidates voted on the best webquest and discussed the value within that which they chose as effective elements in the design of the webquest.

The added value in this assignment upload is not only the educational value of the assignment but the development of inspired understandings and consultative nuances that can be utilized across the digital divide.

The assignment demonstrates to the students that the use of similar technology tools used in the field of teacher education is a global practice and raises the self-efficacy of the teacher candidates, which is linked to positive and repeated positive academic performance [5]. Students from the NHL university were not required to create a webquest. Yet those students took part in the review and voting and learned about other platforms that could be used in the process.

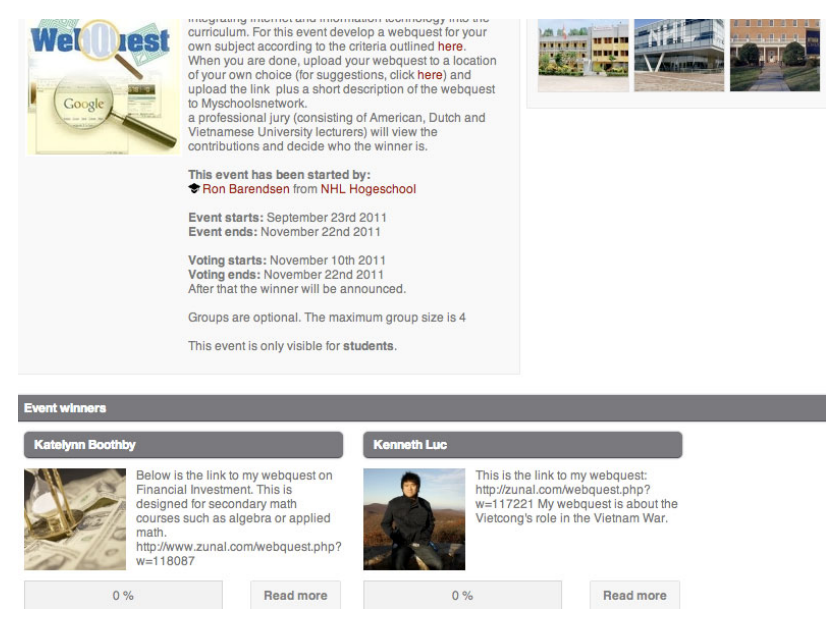

Figure 2.

\section{B. The video-analysis pilot}

The video analysis module is a standard and compulsory part of the MAT curriculum. Its purpose is to identify, examine, and evaluate the characteristics of adolescents as they are portrayed in the popular media in relationship to the specific theories on adolescence presented in the course readings and videos. How accurately are the lives of teenagers portrayed in the everyday? 
Students work in groups to develop a technology "product" (Glogster, a Wiki, a Blog, or a Website) through which they share their group's written and/or oral summary of the movie they chose. The summary will include attention to: the movie's overall plot and major themes; the relevant theories of adolescent typical/atypical development portrayed in the movie's characters; the culture of adolescence as represented in the movie; three to four conclusions that could be drawn (erroneously and/or accurately) about adolescent development based on the movie; and, an assessment of whether or not these conclusions are supported by research presented in the course materials (texts, videos, websites and related activities). Students work together on WEBtycho, the UMUC online collaboration platform; A summary of the project plus the link to the online product is posted on MySchoolsNetwork. This platform also gives other members a chance to ask questions and post comments.

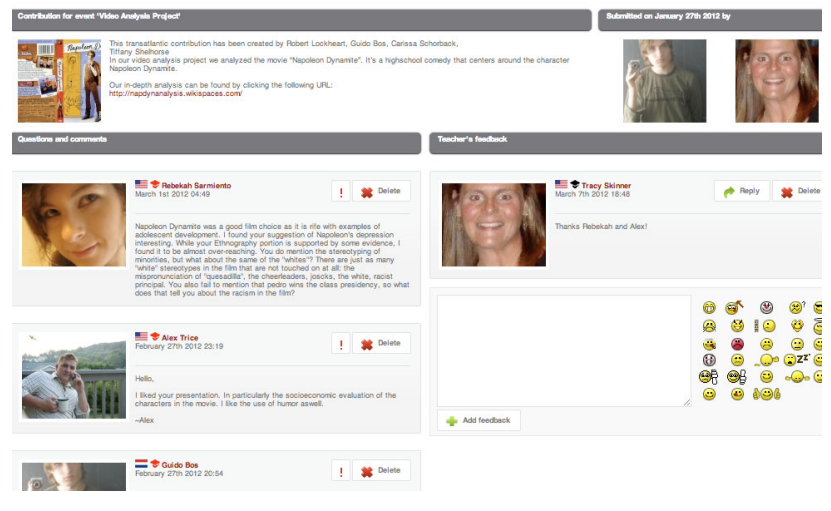

Figure 3.

For the pilot 4 Dutch students were invited to join two MAT project groups. Participation for Dutch students was voluntary. Of the four students two bailed out altogether, one student was in touch with the other group members, took responsibility for part of the project but - as a consequence of unfamiliarity with the platform - failed to upload her part in time. The fourth Dutch students participated as a full member of the group and was in charge of the web design of the final product.

Evaluation : Voluntary participation by Dutch students caused a degree of imbalance in this pilot. The time the students had to familiarize themselves with the new platform WEBtycho was too short. Moreover, there was no adequate socialization phase [4].

The student whose participation was successful has indicated that this was a valuable learning experience for him. He enjoyed the online contact he had with the American project leader, felt appreciated by the other group members and felt it was interesting to enter another Academic reality by means of the internet.

\section{The intervision pilot}

Pilot C attempted to develop a community of practice by eliciting peer feedback about individual dilemmas observed in the classroom at the time when the teacher candidates began their student teaching internship.

The term, intervision, is used to identify the peer upload of dilemmas into MySchoolsNetwork and the analysis and discussions that the teacher candidates had with one on another across the Atlantic ocean. The design of the intervision tool in the MySchoolsNetworks leans rather heavily on Ref. [6]'s seven design principles for Communities of Practice.

1. Design for evolution.

2. Open a dialogue between inside and outside perspectives.

3. Invite different levels of participation.

4. Develop both public and private community spaces.

5. Focus on value.

6. Combine familiarity and excitement.

7. Create a rhythm for the community.

The teacher candidates provided feedback to one another, in English, and recognized that the problems that a new teacher faces in the Netherlands are very similar to the problems that a new teacher faces in the United States.

The overall input received from the teacher candidates in the United States was that the use of the platform was similar to the discussions that they currently are required to have in their online seminar with their fellow MAT students. The cultural aspect of the discussions is what appeared to be more worthwhile to the MAT students in the United States rather than the analysis themselves.

It was assumed that students might benefit from the extra submersion in English educational discourse. According to Ref. [5], the most important result of peer consultation is that contributors build up a shared professional discourse, which will help them to become a confident member of the professional community. The Dutch student group consisted of student teachers of English as a second language so this pilot would provide them with an opportunity of immerse themselves in English education discourse. The UMUC students have no face to face intervision sessions, so the pilot has provided them with an opportunity to share and discuss workplace dilemmas with peers they would not otherwise have had.

Evaluation : This pilot had not ended when this paper was written. Provisional evalution shows that the UMUC students while required to participate in the intervision process, felt that they did not have a true didactic experience with the students from the Netherlands.

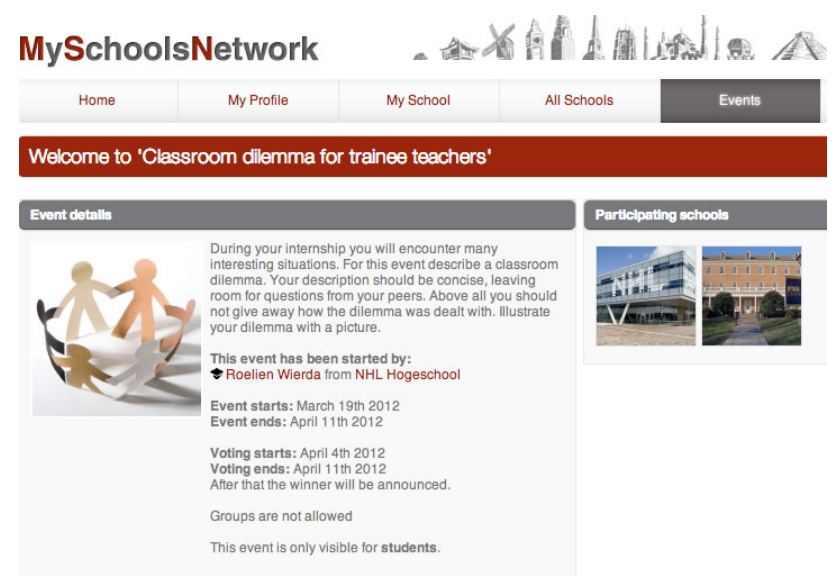

Figure 4.

Even though they have professional discourse with their peers in the WEBtycho online classroom, the amount of time that transpired between the upload of the dilemma and the responses, may have been more time than the UMUC MAT students were used to in their online classroom. 
Provisional evaluation with the Dutch students make clear that Dutch students feel stimulated by the participation and feedback from their peers from the other side of the Atlantic.

The pilot consists of three cycles. Online evidence shows that there is growing interaction between Dutch and American students as the pilot progresses. This shows how important the socialization phase is.

\section{EVALUATION AND DISCUSSION}

The overall objective of the pilots was to find out what the added value of online collaboration might be to student teachers in the USA and the Netherlands.

The pilot objective of the online webquest contest was to provide an introductory event that would allow students from the Netherlands and the United States to interact with one another without requiring any additional work from either group of students. The event enabled students from the United States to complete a requirement of their assignment by sharing their webquest on the web to allow other teacher candidates and teachers the opportunity to critique or use their educational tool with their own students. The event enabled the students from the Netherlands the opportunity to learn about new Web 2.0 technology tools that they could use in their assignments and student teaching, and provided an overall opportunity for the students to develop relationships, both personal and professional.

Based on the results of the webquest pilot, we may conclude that this event was successful in that:

- UMUC MAT students successfully uploaded their webquests.

- Students from the Netherlands reviewed and voted on the webquests and posted comments.

- UMUC MAT students responded somewhat to the students in the Netherlands

- Students from the Netherlands learned about new Web 2.0 tools that they could use to create webquests.

What did not result were any direct relationships established between the students. It is believed that more time is necessary to help the teacher candidates to develop a relationship prior to beginning the intervision process.

The objective of the video analysis pilot was to find out how mixed transatlantic workgroups would function in the UMUC VLE WEBtycho. On the basis of the results we may conclude that a number of conditions will have to be met before such collaboration can be successful.

- Both groups need to be in the module on the same basis, i.e. the module should be part of the curriculum and it should be clear to both groups of students what is in it for them.
- Intensive online collaboration will have to be preceded by a period of online socialization between students and staff.

- Roles, both of students and staff on either side of the Atlantic should be clearly defined before the module starts.

The objective of the intervision project was to develop a community of practice. We will begin to look at empirical data over the course of the Summer 2012 and continue to collect data on this pilot and will modify its implementation for Fall 2012 accordingly.

\section{Future Plans}

We will continue our partnership by continuing to analyze the data on the projects that we have started and determine how they will continue. In addition, we are discussing the possibility of having peer lectures within our teacher education classrooms through the use of technology.

We are considering the idea of peer mentors and perhaps engaging teachers from the MySN to become mentors to the teacher candidates from different countries to enable the students to learn more about global competencies such as interdisciplinary expertise.

\section{REFERENCES}

[1] Bryant, J. (2003). The six dilemmas of collaboration. Chichester, England: John Wiley \& Sons, Ltd.

[2] A guide to UK Universty Higher Education Partnerships for Oversees Universities. UK Higher Education International and Europe Unit, research Series 9. International ( July, 2011)

[3] Jackson, A. (2011) Global Competence: Prepare youth to engage with the world. retrieved March 28, 2012 from: http://asiasociety.org/education/partnership-global-learning/makin g-case/global-competence-prepare-youth-engage-world .

[4] Salmon, Gilly (2002), "E-tivities. The Key to Active Online Learning", London: Tayler \& Francis

[5] Joyce, B. and Showers, B. (2002). Student achievement through staff development. (3rd ed.)Alexandria, VA: Association for Supervision and Curriculum Development.

[6] Wenger, E.; McDermott, R.; Snyder, W.M. (2002). Cultivating Communities of Practice. Boston: Harvard Business School Press. pp. 304.

\section{AUTHORS}

First A. Barbara Schwartz-Bechet is with the Univeristy of Maryland University College, Adelphi, MD, USA (e-mail: bschwartz-bechet@umuc.edu).

Second B. Roelien Bos-Wierda is with the NHL University of applied sciences, Leeuwarden, 8900 CA Netherlands (e-mail: r.wierda@ iec.nhl.nl).

Third C. Ron Barendsen is with the NHL University of applied sciences, Leeuwarden, 8900 CA Netherlands (e-mail: r.m.barendsen@iec.nhl.nl).

Manuscript received 30 March 2012. Published as resubmitted by the authors 7 August 2012. 